LWSA

Local Wisdom, Social, and Arts

PAPER - OPEN ACCESS

\title{
Gambaran Stres Akulturasi Mahasiswa Papua yang Menjalani Perkuliahan di Universitas Sumatera Utara
}

\author{
Author : Chyntia Septiani Sinaga \\ DOI $\quad: 10.32734 /$ lwsa.v1i1.175 \\ Electronic ISSN : 2654-7058 \\ Print ISSN : :2654-7066
}

Volume 1 Issue 1 - 2018 TALENTA Conference Series: Local Wisdom, Social and Arts

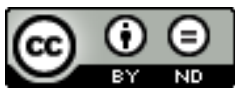

This work is licensed under a Creative Commons Attribution-NoDerivatives 4.0 International License.

Published under licence by TALENTA Publisher, Universitas Sumatera Utara
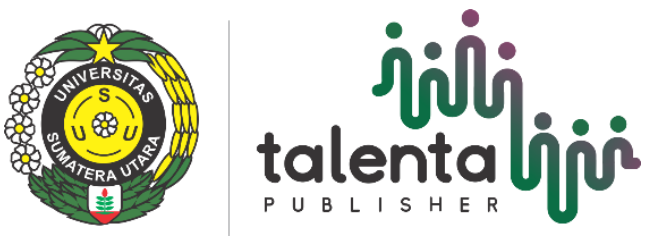


\title{
Gambaran Stres Akulturasi Mahasiswa Papua yang Menjalani Perkuliahan di Universitas Sumatera Utara
}

\author{
Chyntia Septiani Br. Sinaga ${ }^{\text {a }}$, Nunung F. Sitepu ${ }^{a}$ \\ a"Fakultas Keperawatan, Universitas Sumatera Utara, Medan-2015" \\ chyntia.septiani94@yahoo.co.id
}

\begin{abstract}
Papuan students who are ongoing class at the University of North Sumatra are Papua affirmation students and West Papua who had opportunity to continue their education into the State University through affirmation Scholarship Program of Higher Education in cooperation with The Ministry of Education and Culture and research and technology of Higher Education. In different cultures and new environment allow them to acculturate and in its process have variety of challenges, obstacles and difficulties experienced by Papua students. Having adaptation to new potential culture lead acculturation stress. This study aims to know the acculturation stress of Papua students who are ongoing class at the University of North Sumatra. This study used descriptive design, with 56 Papua students as sample. This study used total sampling techniques and questionnaires as instrument. The result of this study showed that Papua students experienced acculturation stress in low category is 52 people (92.9\%) and high category is 4 people $(7.1 \%)$. This result expected to the University, particular for nursing education institutions to provide introduction about culture for new Papua students Affirmations and West Papua when have matriculation so that making them easier in adapting and to anticipate the acculturation stress.
\end{abstract}

Keywords: Acculturation Stress, Papua Students

\section{Pendahuluan}

Pemerataan pembangunan di Indonesia saat ini telah diwujudkan melalui program beasiswa yang ditawarkan oleh perusahaan maupun lembaga dengan memberikan biaya pendidikan gratis bagi siswa berprestasi dan beasiswa peningkatan potensi akademik. Beasiswa tidak hanya dapat dinikmati oleh mahasiswa dari kota-kota besar saja, namun kini telah muncul program beasiswa yang memfasilitasi putra-putri bangsa terutama yang berada di daerahdaerah terluar yang sulit dalam akses pendidikan (Ariani, 2015).

Beasiswa Afirmasi Dikti (ADik) menjadi solusi bagi putra-putri asli Papua untuk melanjutkan jenjang pendidikan yang lebih tinggi di Perguruan Tinggi Negeri (PTN) di Indonesia. Program tersebut berlandaskan pada Peraturan Presiden Nomor 65 Tahun 2011 tentang Percepatan Pembangunan Provinsi Papua dan Provinsi Papua Barat yang berbunyi "Unit Percepatan Pembangunan Provinsi Papua dan Provinsi Papua Barat, yang selanjutnya disebut UP4B, adalah lembaga yang dibentuk untuk mendukung koordinasi, memfasilitasi dan mengendalikan pelaksanaan Percepatan Pembangunan Provinsi Papua dan Provinsi Papua Barat".

Beasiswa Afirmasi Dikti (ADik) adalah beasiswa hasil kerjasama Kemdikbud, Unit Percepatan Pembangunan Provinsi Papua dan Papua Barat (UP4B), dan Majelis Rektor PTN Indonesia, dalam rangka meningkatkan sumber daya manusia di Papua dan Papua Barat (Sumber: website resmi UP4B http://up4b.go.id). 
Implikasi dari adanya program beasiswa ini mengharuskan para mahasiswa asli Papua keluar dari Papua dan tinggal di daerah-daerah tempat mahasiswa melanjutkan pendidikan di universitas- universitas negeri yang tersebar di Indonesia. Beasiswa ini diselenggarakan mulai tahun 2012 bekerja sama dengan 32 PTN di Indonesia. Tahun 2014 jumlah Perguruan Tinggi Negeri yang bergabung dengan program beasiswa ini mengalami pertambahan menjadi 39 PTN yang tersebar diseluruh Indonesia (Sumber: website resmi UP4B http://up4b.go.id).

Universitas Sumatera Utara (USU) merupakan salah satu dari 39 Perguruan Tinggi Negeri (PTN) yang menerima mahasiswa dari Papua melalui program beasiswa Afirmasi Dikti (ADik). Sejak tahun 2012 hingga penerimaan mahasiswa baru 2015 terdapat 58 mahasiswa Papua yang aktif kuliah di USU. Semua mahasiswa tersebut diterima melalui jalurseleksi nasional SNMPTN.Mahasiswa Papua yang menerima beasiswa Afirmasi Dikti (ADik) di USU harus pindah dan menjalani kehidupan yang baru sebagai mahasiswa USU. Kehadiran mahasiswa Papua di USU memberikan nuansa baru dalam dunia pendidikan perguruan tinggi di USU.

Mahasiswa Papua mulai angkatan 2012 hingga angkatan 2015 menetap di lingkungan USU dengan segala aspek sosial budaya yang berbeda dari tempat asal mahasiswa Papua.Tinggal atau kuliah di tempat masyarakat yang berbeda secara sosial dan budaya kemungkinan memunculkan dampak sosial psikologis tertentu. Salah satu dampak sosial-psikologis yang biasa terjadi adalah beradaptasi dengan lingkungan yang baru. Perbedaan bahasa, nilai, dan kebiasaan, diluar persoalan iklim geografis, menjadi hambatan utama (Wijanarko \& Safiq, 2013). Oleh karena itu banyak hal yang dirasakan oleh mahasiswa asal Papua berubah dari kesehariannya di Papua. Mulai terjadi perbedaan adat-istiadat, makanan, minuman, bahasa, lingkungan dan sosial yang berbeda.

Ariani (2015) menunjukkan dalam penelitian kualitatifnya bahwa mahasiswa Papua yang menerima beasiswa Afirmasi Dikti (ADik) di Unnes mengalami hambatan sosial budaya pada saat berkuliah di Unnes. Hasilnya menunjukkan hambatan yang dialami mahasiswa Papua adalah : 1) kurangnya pengetahuan dan bekal mahasiswa Papua mengenal Unnes; 2) perbedaan makanan; 3) perbedaan gaya berpenampilan; 4) Homesick; 5) stereotip dan diskriminasi; serta 6) perbedaan bahasa. Hambatan tersebut memunculkan dampak psikologis dalam diri personal maupun khidupan sosial mereka.

Wijanarko \& Safiq (2013) menyimpulkan dalam penelitiannya bahwa mahasiswa luar pulau yang berasal dari Papua di Surabaya mengalami berbagai hambatan dalam menyesuaikan diri. Hambatan tersebut adalah adanya perbedaan bahasa, karakteristik fisik, dan kebiasaan budaya dengan masyarakat lokal.

Hambatan-hambatan tersebut memunjulkan dampak psikologis dalam diri personal maupun kehidupan sosial mereka. Dari hasil wawancara peneliti dengan ketua Afirmasi Papua dan Papua Barat di USU, bahwa sudah ada 2 orang yang meninggal dunia pada tahun 2015 akibat hambatan yang dirasakan selama proses akulturasi. Hambatan yang dirasakan tersebut adalah perbedaan makanan \& minuman karena sudah terbiasa enak makan makanan khas Papua (sagu, ubi) sehingga pada saat di medantidak selera makan karena tidak cocok dengan makanan di medan,juga disebabkan karena kebiasaan minum minuman beralkohol, dan hambatan bahasa juga terjadi terhadap sosialnya sehingga merasakan kesulitan

dalam berkomunikasi dengan sosial untuk mecari pelayanan kesehatan. Tujuan dari penelitian ini adalah untuk mengetahui stres akulturasi mahasiswa Papua yang menjalani perkuliahan di Universitas Sumatera Utara.

\section{Metode Penelitian}

Desain penelitian yang digunakan dalam penelitian ini bersifat deskiptif menggunakan teknik total sampling dengan sampel penelitian 56 orang. Penelitian ini dilakukan di lingkungan Universitas Sumatera Utara. Waktu penelitian dilaksanakan pada bulan Oktober 2015-Juli 2016. Analisa data

dengan menggunakan frekuensi dan persentase. 


\section{Hasil penelitian dan pembahasan}

\subsection{Hasil penelitian}

Tabel 1. Distribusi frekuensi dan persentase kategori stres akulturasi mahasiswa Papua yang menjalani perkuliahan di Universitas Sumatera Utara $(\mathrm{n}=56)$

\begin{tabular}{lll}
\hline Variabel Stres Akulturasi Mahasiswa Papua & Frekuensi & Persentase (\%) \\
\hline Stres akulturasi rendah & 52 & 92,9 \\
Stres akulturasi tinggi & 4 & 7,1 \\
Total & 56 & 100 \\
\hline
\end{tabular}

Dari hasil ditemukan yaitu stres akulturasi mahasiswa Papua dalam kategori rendah sebanyak 52 orang (92,9\%) dan dalam kategori tinggi yaitu sebanyak 4 orang $(7,1 \%)$.

Tabel 2. Distribusi frekuensi dan persentase crosstabs stres akulturasi mahasiswa Papua yang menjalani perkuliahan di Universitas Sumatera Utara dengan jenis kelamin $(\mathrm{n}=56)$

\begin{tabular}{|c|c|c|c|c|c|c|}
\hline \multirow{2}{*}{$\begin{array}{l}\text { Variabel Stres Akulturasi Mahasiswa } \\
\text { Papua }\end{array}$} & \multicolumn{3}{|c|}{ Jenis Kelamin } & \multicolumn{3}{|c|}{ Jumlah } \\
\hline & $\mathrm{R}$ & $\%$ & $\mathrm{~T}$ & $\%$ & $\mathrm{n}$ & $\%$ \\
\hline Laki-laki & 23 & 41,1 & 3 & 5,3 & 26 & 46,4 \\
\hline Perempuan & 29 & 51,8 & 1 & 1,8 & 30 & 53,6 \\
\hline
\end{tabular}

Dari hasil ditemukan yaitu stres akulturasi mahasiswa Papua dalam kategori rendah sebanyak 52 orang $(92,9 \%)$ terdiri dari 23 orang $(41,1 \%)$ berjenis kelamin laki-laki dan 29 orang $(51,8 \%)$ berjenis kelamin perempuan, kemudian stres akulturasi mahasiswa Papua dalam kategori tinggi sebanyak 4 orang $(7,1 \%)$ terdiri dari 3 orang $(5,3 \%)$ berjenis kelamin laki-laki dan 1 orang $(1,8 \%)$ berjenis kelamin perempuan.

Tabel 3. Distribusi frekuensi dan persentase crosstabs stres akulturasi mahasiswa Papua yang menjalani perkuliahan di Universitas Sumatera Utara dengan umur $(n=56)$

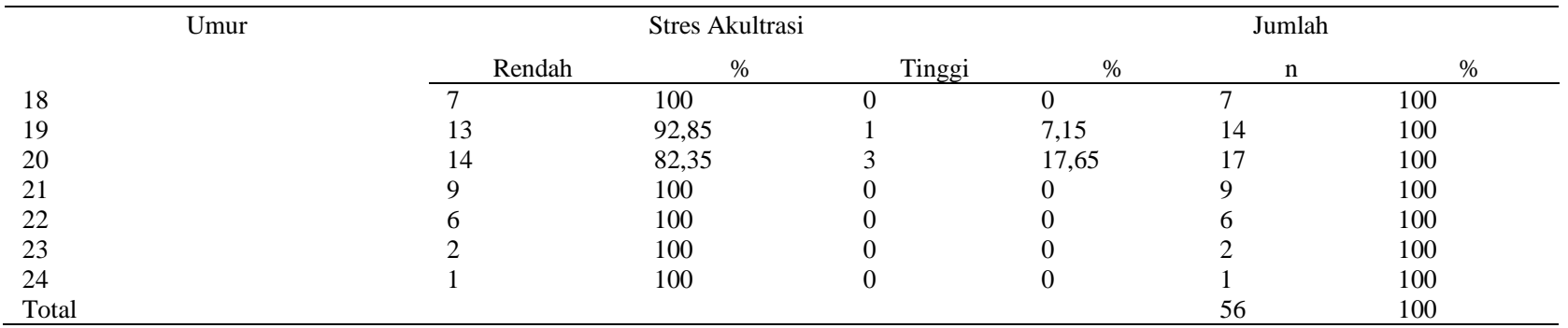

Dari hasil ditemukan yaitu dengan kategori stres akulturasi rendah, pada umur 18 tahun terdapat 7 orang (100\%), pada umur 19 tahun terdapat 13 orang $(92,85 \%)$, pada umur 20 tahun terdapat 14 orang $(82,35 \%)$, pada umur 21 tahun terdapat 9 orang (100\%), pada umur 22 tahun terdapat 6 orang (100\%), pada umur 23 tahun terdapat 2 orang $(100 \%)$, pada umur 24 tahun terdapat 1 orang $(100 \%)$. Sedangkan untuk kategori stres akulturasi tinggi terdapat pada umur 19 tahun sebanyak 1 orang $(7,15 \%)$ dan pada umur 20 tahun sebanyak 3 orang $(17,65 \%)$.

Tabel 4. Distribusi frekuensi dan persentase crosstabs stres akulturasi mahasiswa Papua yang menjalani perkuliahan di Universitas Sumatera Utara dengan stambuk $(\mathrm{n}=56)$

\begin{tabular}{|c|c|c|c|c|c|c|}
\hline \multirow[t]{2}{*}{ Stambuk } & \multicolumn{3}{|c|}{ Stres Akultrasi } & \multicolumn{3}{|c|}{ Jumlah } \\
\hline & $\mathrm{R}$ & $\%$ & $\mathrm{~T}$ & $\%$ & $\mathrm{n}$ & $\%$ \\
\hline 2012 & 11 & 100 & 0 & 0 & 11 & 100 \\
\hline 2013 & 9 & 100 & 0 & 0 & 9 & 100 \\
\hline 2015 & 21 & 100 & 0 & 0 & 21 & 100 \\
\hline Total & & & & & 5 & 100 \\
\hline
\end{tabular}


Dari hasil ditemukan yaitu stres akulturasi mahasiswa Papua dalam kategori rendah terdiri dari 11 orang (100\%) pada stambuk 2012, 9 orang $(100 \%)$ pada stambuk 2013, 11 orang $(73,3 \%)$ pada stambuk 2014, dan 21 orang (100\%) stambuk 2015. Sedangkan stres akulturasi mahasiswa Papua dengan kategori tinggi, berasal pada stambuk 2014 sebanyak 4 orang $(26,7 \%)$.

\subsection{Pembahasan}

Hasil penelitian yang didapatkan yaitu bahwa sebagian besar mahasiswa Papua yang menjalani perkuliahan di Universitas Sumatera Utara mengalami stres akulturasi dengan kategori rendah yaitu sebanyak 52 orang $(92,9 \%)$, dan hanya 4 orang $(7,1 \%)$ yang mengalami stres akulturasi dengan kategori tinggi. Hasil tersebut bertentangan dengan penelitian Hapsari \& Primastuti (2014) yang menyatakan bahwa Mahasiswa Papua merasa kesulitan untuk bersosialisasi di lingkungan orang-orang yang berasal dari daerah lain, seperti disaat perkuliahan ia merasa kesulitan untuk mendapatkan kelompok untuk mengerjakan tugas, bahkan pernah sampai tidak mendapatkan kelompok dan mengerjakannya sendirian. Namun dari hasil tersebut juga didapatkan bahwa ada beberapa mahasiswa Papua yang menjalani perkuliahan di Universitas Sumatera Utara yang mungkin karena faktor individunya belum mampu untuk beradaptasi/ akulturasi yang rendah yang ditandai adanya reaksi negatif yang mereka rasakan dari masyarakat dan mahasiswa lokal (yang bukan Papua) sehingga membuat mereka mudah tegang (emosi) dan lebih memilih untuk lebih sering berkumpul dan berinteraksi dengan mahasiswa satu etnis dengan mereka.

Berdasarkan hasil penelitian didapat bahwa responden yang berjenis kelamin perempuan sebanyak 30 orang $(53,6 \%)$ sebagian besar mengalami stres akulturasi rendah yaitu sebanyak 29 orang $(51,8 \%)$. Hasil tersebut didukung oleh penelitian sebelumnya yang menyatakan bahwa mahasiswa berjenis kelamin perempuan memiliki keterampilan sosial yang lebih baik untuk mengatasi stres akulturasi/lebih kompromi (Pacleb \& Collins, 2014).Berdasarkan hasil penelitian juga menunjukkan bahwa dari 4 orang $(7,1 \%)$ yang mengalami stres akulturasi tinggi, 3 orang $(5,3 \%)$ diantaranya berjenis kelamin laki-laki. Hal tersebut menunjukkan bahwa laki-laki memiliki resiko lebih tinggi untuk mengalami stres akulturasi dengan kategori tinggi dibandingkan perempuan. Hasil yang didapatkan juga didukung oleh penelitian sebelumnya yang menyatakan bahwa mahasiswa laki-laki memiliki sifat dominan yang sering menimbulkan konflik dari berbagai budaya (stres akulturasi dan memiliki keterampilan sosial yang rendah dari pada perempuan (Pacleb \&Collins,2014).

Hasil penelitian menunjukkan bahwa responden terbanyak terdapat pada umur 20 tahun (17 orang) yaitu remaja akhir yang berkontribusi tinggi dalam mengalami stres akulturasi rendah sebanyak 14 orang $(82,35 \%)$ dan juga berkontribusi tinggi dalam mengalami stres akulturasi tinggi sebanyak 3 orang (17,65\%). Pada umur remaja akhir terjadi perkembangan mental yang pesat. Perkembangan mental pada usia remaja akhir mengakibatkan kemampuan remaja untuk menghipotesis apapun yang berhubungan dengan hidupnya dan lingkungannya juga meningkat (Wong's \& Hockenberry, 2007).

Hasil penelitian yang diperoleh juga menunjukkan bahwa responden pada angkatan pertama tahun 2012 sebanyak 11 orang $(100 \%)$ seluruhnya memiliki tingkat stres akulturasi rendah sama dengan angkatan 2015 sebanyak 21 orang (100\%) yang merupakan angkatan pertama sekali yang terpapar dengan lingkungan baru yang seluruhnya juga memiliki stres akulturasi rendah.Hal ini menunjukkan bahwa tidak ada perbedaan stres akulturasi yang signifikan yang dirasakan oleh mahasiswa Papua tahun 2015 yang baru terpapar dengan lingkungan yang baru. Hasil tersebut berbanding terbalik dengan penelitian sebelumnya yang mendapatkan hasil bahwa lingkungan merupakan faktor tertinggi penyusun stres pada mahasiswa tahun pertama dimana mahasiswa merasakan sulit untuk beradaptasi saat memasuki lingkungan dan suasana baru (Nurmaningtyasih, 2015)

\section{Simpulan dan saran}

\subsection{Simpulan}

Mahasiswa Papua yang menjalani perkuliahan di USU sebagian besar mengalami stres akulturasi dengan kategori rendah yang membuktikan bahwa mereka mampu bersosialisasi dan tidak memiliki masalah patologis dalam menjalani perkuliahan di USU serta membuktikan bahwa menjalani perkuliahan di tempat yang berbeda jauh dengan budaya dan lingkungan tempat tinggal (terkhusus USU) tidak terlalu berpengaruh membuat stres akulturasi mereka meningkat.Namun masih ada beberapa, yang mungkin karena faktor individunya yang belum mampu beradaptasi/ 
akulturasi yang kurang merasakan reaksi negatif dari masyarakat dan mahasiswa lokal (yang bukan Papua) yang membuat mereka merasa tidak nyaman yang ditandai dengan mudahnya mereka tegang (emosi) terhadap reaksi negatif dari mahasiswa dan masyarakat lokal (yang bukan Papua) tersebut dan lebih memilih untuk lebih sering berkumpul dan berinteraksi dengan mahasiswa satu etnis dengan mereka (Papua).

\subsection{Saran}

Bagi pendidikan keperawatan khususnya keperawatan jiwa dan komunitas perlu diberikan pengenalan budaya kepada para mahasiswa baru Afirmasi Papua dan Papua Barat pada saat matrikulasi sehingga membantu mereka dalam mengenal dan beradaptasi dengan lingkungan dan budaya baru dan meminimalkan terjadinya stres akulturasi pada mahasiswa baru Afirmasi Papua dan Papua Barat yang menjalani perkuliahan di USU.

\section{References}

[1] Ariani, N. (2015). Strategi Adaptasi Sosial Budaya Mahasiswa Papua Penerima Beasiswa Afirmasi

[2] Dikti (ADIK) Tahun 2013 Di Universitas Negeri Semarang. Semarang: Skripsi Pendidikan Sosiologi dan Antropologi.

[3] Hapasari, A., \& Primastuti, E. (2014). Kepercayaan Diri Mahasiswi Papua Ditinjau dari Dukungan Teman Sebaya. Jurnal Psikologi Psikodimensia. Vol. 13 No. 1. Semarang: Fakultas Psikologi Universitas Katolik Soegijapranata.

[4] Nurmaningtyasih, I. (2015). Stres Mahasiswa Tahun Pertama UIN Maulana Malik Ibrahim Malang. Malang: Skripsi Fakultas Psikologi Jurusan Psikologi.

[5] Pacleb, S \& Collins J. (2014). The Relationship of Acculturation Stress and Leisure Satisfaction of Hispanic College Students. American International Journal of Contemporary Research. Vol.4, No. 4. United States of America. Sumber: website resmi UP4B http://up4b.go.id

[6] Wijanarko, E. \& Syafiq, M. (2013). Studi Fenomenologi Pengalaman Penyesuaian Diri Mahasiswa Papua Di Surabaya. Jurnal Psikologi : Teori \& Terapan, Vol. 3 No. 2.

[7] Wong's \& Hokenberry. (2007). Wongees Nursing Care og Infants and Children. (8 ed.). Canada: Mosby Elsevier. 